\title{
Akut hiperkapnik solunum yetmezliğinde noninvaziv mekanik ventilasyon yanıtı sonrasında erken dönem geri dönüşümlü respiratuvar asidoz gelişen hastaların analizi
}

\section{Analysis of patients with reversible respiratory acidosis after noninvasive mechanical ventilation response in acute hypercapnic respiratory failure}

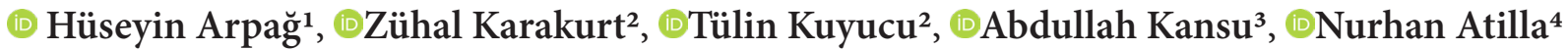 \\ ${ }^{1}$ Özel Batman Medical Park Hastanesi, Göğüs Hastalıkları Bölümü, Batman, Türkiye \\ ${ }^{2}$ İstanbul Süreyyapaşa Gögüs Hastalıkları ve Göğüs Cerrahisi Eğitim ve Araştırma Hastanesi, Göğüs Hastalıkları ve Yoğun Bakım Kliniği, \\ İstanbul, Türkiye \\ ${ }^{3}$ Medipol Üniversitesi Tip Fakültesi, Göğüs Hastalıkları Anabilim Dalı, İstanbul, Türkiye \\ ${ }^{4}$ Kahramanmaraș Sütçü İmam Üniversitesi, Tip Fakültesi Göğüs Hastalıkları Anabilim Dalı, Kahramanmaraş, Türkiye
}

Cite this article as/Bu makaleye atıf için: Arpağ H, Karakurt Z, Kuyucu T, Kansu A, Atilla N. Akut hiperkapnik solunum yetmezliğinde noninvaziv mekanik ventilasyon yanıtı sonrasında erken dönem geri dönüşümlü respiratuvar asidoz gelişen hastaların analizi. J Med Palliat Care 2020; 1(4): 103-108.

\begin{abstract}
ÖZ
Amaç: Bu çalışmada akut hiperkapnik solunum yetmezliği (AHSY) tanısı ile yoğun bakım ünites (YBÜ)'inde noninvaziv mekanik ventilasyon (NIMV) uygulamasına ilk saatlerde iyi yanıt alınan, ancak nazal oksijene geçildikten kısa süre sonra tekrar ciddi solunumsal asidoz gelişen hastaların analizini yapmayı planladık.

Gerec ve Yöntem: Ocak 2009-Nisan 2010 tarihleri arasında, AHSY ( $\mathrm{pH}<7,35$ ve $\mathrm{PaCO}_{2}>45 \mathrm{mmHg}$ ) nedeniyle YBÜ’de takip edilen ve uygulanan ilk 1-4 saatlik NIMV tedavisine yanıt veren 139 hastanın verisi retrospektif olarak incelendi. Hastalar, NIMV tedavisi sonlandırıldıktan sonraki takiplerinde rebound hiperkapni gelişen (grup 1) ve gelişmeyen (grup 2) olmak üzere iki gruba ayrıldı. Hastaların demografik özellikleri, AHSY nedenleri, NIMV uygulama süreleri, arteriyel kan gazı (AKG) değerleri, APACHE-II ve SOFA skorları, hastanede yatıss süresi (gün), invaziv mekanik ventilatör (İMV) ihtiyacı ve yaşam durumları kaydedildi. Grupların özelliklerini karșılaștırmada numerik veriler için nonparametrik Mann-Withney-U testi ve kategorik veriler için Ki-kare testi kullanıldı.

Bulgular: Çalışmaya 139 hasta dâhil edildi. Grupların demografik özellikleri ve NIMV süreleri, YBÜ ve hastane kalış süreleri arasında fark bulunmadı. Grup 1'de toraks deformitesi-kas hastalıkları (grup 1'de \%8,6; grup 2'de \%1,2) ve obezite hipoventilasyon sendromu (OHS) (grup 1'de \%17,2; grup 2'de \%9,9) daha fazla iken; grup 2'de parankimal akciğer hastalıkları fazla (grup 1'de \%6,9; grup 2'de \%18,5) idi. Her iki grup için evde oksijen ve NIMV cihazı kullanıyor olma durumları benzerdi. Grupların $\mathrm{pH}$ ve $\mathrm{PaCO}_{2}$ değerleri YBÜ’ye kabul esnasında benzerken, ilk kontrolde grup l'de grup 2'ye göre belirgin düzelme varken (sırasılyla $\mathrm{p}<0,005$ ve $\left.\mathrm{p}<0,039\right)$ nazal oksijene geçilmesiyle grup 1'de belirgin kötüleşme görüldü (sırasıyla $\mathrm{p}<0,0001$ ve $\mathrm{p}<0,0001$ ); ancak YBÜ çlkış AKG değerleri iki grup arasında benzerdi. Her iki grubun YBÜ kalış günleri grup 1'de 8 (5-12) gün; grup 2'de 6 (4-10) gün olarak benzer bulundu. Grup 1 ve 2'de YBǗde IMV'ye geçis (sırasıyla \%10,3; \%7,4, p>0,53) ve mortalite oranları (sirasiyla $\% 6,9 ; \% 9,9, \mathrm{p}>0,38$ ) benzer saptand..

Sonuç: Çalışmamızda toraks deformitesi-kas hastalıkları ve OHS’nin eşlik ettiği AHSY olan hastalarda NIMV uygulanmasına hızlı klinik yanıt alındığını ancak nazal oksijene geçildikten kısa süre sonra AKG değerlerinin kötüleștiğini saptadık. Bu hasta grubunda NIMV uygulaması sonrası hızlı düzelme yanıltıcı olmamalıdır. Özellikle acil servisten yatışı planlanan bu hastalar nazal oksijen tedavisine geçilse bile mutlaka monitörize edilerek yakın takibe alınmalıdır.

Anahtar Kelimeler: Noninvaziv mekanik ventilasyon, respiratuvar asidoz, hiperkapni, yoğun bakım
\end{abstract}

\begin{abstract}
Aim: In this study, we aimed to analyze patients with a diagnosis of acute hypercapnic respiratory failure (AHRF) who responded to noninvasive mechanical ventilation (NIMV) in the intensive care unit (ICU) in the first hours but developed severe respiratory acidosis again soon after switching to nasal oxygen.

Material and Method: Between January 2009 and April 2010, data of 139 patients who were followed up in the ICU due to AHRF (pH $<7.35$ and PaCO $>45$ mmHg) and responded NIMV treatment in the first 1-4 hours, were analyzed retrospectively. Patients were divided into two groups as those with rebound hypercapnia (group 1) and those without rebound hypercapnia (group 2) in their follow-up after the termination of NIMV treatment. Demographic characteristics of the patients, causes of AHRF, duration of NIMV administration, arterial blood gas (ABG) values, APACHE II and SOFA scores, duration of hospitalization (days), need for invasive mechanical ventilation (IMV) and life situations were recorded. Nonparametric Mann-Withney-U test was used for numerical data and Chi-square test for categorical data was used to compare the properties of the groups.

Results: 139 patients were included in the study. There was no difference between the demographic characteristics of the groups and the duration of NIMV use, and the length of stay in the ICU and hospital. Thoracic deformity-muscular diseases (8.6\% in group 1, 1.2\% in group 2), and obesity hypoventilation syndrome (OHS) (17.2\% in group $1,9.9 \%$ in group 2 ) were more in group 1, parenchymal lung diseases was higher in group 2 (6.9\% in group $1,18.5 \%$ in group 2$)$. The situation of using oxygen and NIMV devices at home was similar for both groups. While the $\mathrm{pH}$ and $\mathrm{PaCO}_{2}$ values of the groups were similar during ICU admission, there was a significant improvement in group 1 compared to group 2 at the first control $(\mathrm{p}<0.005, \mathrm{p}<0.039$ respectively), while a significant deterioration was observed in group 1 after switching to nasal oxygen $(\mathrm{p}<0.0001, \mathrm{p}<0.0001$ respectively). However, $\mathrm{ABG}$ values at ICU discharge were similar between the two groups. ICU stay days of both groups were found to be similar as $8(5-12)$ days in group 1 and $6(4-10)$ days in group 2 . Necessity of IMV $(10.3 \% ; 7.4 \%$, p $>0.53$ respectively) and mortality rates $(6.9 \%$; $9.9 \%$ p $>0.38$ respectively) in group 1 and 2 were found similar.

Conclusion: In our study, we determined that patients with AHRF accompanied by thoracic deformity-muscle diseases and OHS had a rapid clinical response to NIMV administration, but ABG values rapidly deteriorated after switching to nasal oxygen. In this patient group, rapid improvement after NIMV application should not be misleading. Especially, patients who are planned to be hospitalized from the emergency department should be monitored and followed closely after switching to nasal oxygen therapy.

Keywords: Respiratory acidosis, noninvasive mechanical ventilation, hypercapnia, intensive care
\end{abstract}




\section{GİRIş}

Solunum yetmezliği (SY) tedavisinde uygun endikasyonda noninvaziv mekanik ventilasyon (NIMV) uygulanması 2006 yılında \%16 civarında iken; günümüzde yaklaşı \%42 civarındadır (1-4). NIMV başarı belirteçleri dikkate alındığında, NIMV uygulama endikasyonları her geçen gün genişlemektedir $(1,4)$. Hiperkapni tedavisinde başarılı bir yöntem olan NIMV'in, İMV ihtiyacını azalttığı, yoğun bakım yatış süresini kısalttığ ${ }_{1}$ ve mortaliteyi azalttığ bildirilmektedir $(3,5,6)$. NIMV yanıtı ilk 1-4 saat içinde hastanın kliniği ile birlikte arter kan gazı (AKG)'na bakılarak kontrol edilir (7,8-10). NIMV başarı belirteçleri varlığında ve klinik duruma göre hastanın bundan sonraki takibinin nerede yapılacağına karar verilir. Yapılan çalışmalarda dakikalar ile bir saat içinde ortaya çıkan başarısızlıklar hızlı başarısızlık, 1-48 saat içerisinde ortaya çıkan başarısızlıklar erken başarısızlık, 48 saatten sonra ortaya çıkan başarısızlıklar ise geç başarısızlık olarak tanımlanmıştır $(11,12)$. NIMV başarısının en önemli göstergeleri solunum sayısı ve $\mathrm{PaCO}_{2}$ değerinde düşme, $\mathrm{pH}$ ve oksijenasyonda düzelmedir (13). NIMV günümüzde yoğun bakım ünitesi (YBÜ) ve ara YBÜ dışında, acil servislerde ve kliniklerde de başarı ile uygulanmaktadır. Ancak AKG'de $\mathrm{pH}<7,25, \mathrm{PaCO}_{2}>90 \mathrm{mmHg}$ olan ve ileri monitörizasyon gereken hastaların yüksek entübasyon riski nedeni ile YBÜ'de izlenmesi önerilir $(9,10)$. NIMV başarı ve başarısızlı̆̆ ile ilgili çeşitli çalışmalar mevcut olup bu çalışmalarda NIMV endikasyonları, komplikasyonları, başarı ve başarısızlığını etkileyen faktörler incelenmiștir (12). Altta yatan nedene göre değişmekle beraber NIMV başarısızlı̆̆ $\quad \% 5-60$ olarak bildirilmiştir $(12,14,15)$. Merkezimiz YBÜ’de akut hiperkapnik solunum yetmezliği (AHSY) nedeniyle uygulanan NIMV tedavisine erken dönem iyi yanıt alınan, ancak nazal oksijene geçildikten kısa süre sonra karbondioksit değerlerinde yükselme gelişen hastaların demografik özelliklerini belirlemek ve NIMV yanıtındaki geçiciliği öngörmek amacıyla bu çalışmayı planladık.

\section{GEREÇ VE YÖNTEM}

Araştırmamız retrospektif gözleme dayalı kohort çalışma olarak planlanmıştır.

\section{Etik Durum}

Çalışmamız Süreyyapaşa Göğüs Hastalıkları ve Göğüs Cerrahisi Eğitim ve Araştırma Hastanesi Etik Kurulu tarafından onaylanmıştır (2011/2). Çalışmamızda güncel Helsinki Bildirgesi’ne bağlı kalınmıştır.

\section{Dahil Edilme Kriterleri}

Ocak 2009-Nisan 2010 tarihleri arasında Süreyyapaşa Gögüs Hastalıkları ve Göğüs Cerrahisi Eğitim ve Araştırma Hastanesi YBÜye interne edilen, NIMV endikasyonu olan, klinik ve AKG bulguları AHSY ile uyumlu olup ilk 24 saat NIMV uygulanan hastalar çalışmaya dahil edildi.

\section{Dahil Edilmeme Kriterleri}

Terminal dönem hastalıkları (akciğer kanseri, klinik radyolojik harap olmuş akciğer hastalıkları, interstisyel fibrozis olan hastalar, ilk AKG'de yanıt olmayıp entübe edilen hastalar, $\mathrm{AKG}$ de $\mathrm{PaCO}_{2}<45$ ve metabolik asidozu olan hastalar çalışmaya alınmadı.

\section{NIMV Başarı Kriterleri}

Arter kan gazında $\mathrm{PaCO}_{2}$ 'de azalma, $\mathrm{PaO}_{2} / \mathrm{FiO}_{2}$ 'de düzelme gözlenmesi, arteriyel kan gazından bağımsız olarak ise solunum sayısının azalması, oksijen ihtiyacının azalmasi $(9,10)$.

\section{NIMV Başarısızlık Kriterleri}

NIMV uyumsuzluk, bilinç durumunun düzelmemesi (Glaskow Koma Skalasının $<11$ olması), entübasyon endikasyonu olan klinik tablonun gelişmesi (kardiak arrest, $A K G$ 'de ciddi respiratuvar asidoz $\mathrm{pH}<7,10$, ağ $1 \mathrm{z}$ dolusu kusma ve mide bulantısı, aşırı sekresyon nedeni ile NIMV'nin etkili olmadığı hastalar, NIMV'ye 20 saattten fazla ihtiyaç duyan ileri solunum yetmezliği hastaları (7$10)$.

\section{Arter Kan Gazı}

Arter kan gazı analizi, 45 derece yarı oturur pozisyonda, sterilize ve en az 0,1 ml heparin ile yıkanmış olan enjektör ile Allen testi sonrasında radial arter ponksiyonuyla alınan kandan çalışıldı. AKG ölçümü için hastanemiz YBÜ̉de Bayer Rapidlab 348 marka AKG ölçüm cihazı kullanıldı. Veri çıktısı olarak $\mathrm{PaO}_{2}, \mathrm{PaCO}_{2}, \mathrm{pH}, \mathrm{HCO}_{3}$, baz fazlalığ 1 ve oksijen saturasyon yüzdesi $\left(\% \mathrm{SaO}_{2}\right)$ parametreleri kullanıldı.

\section{Hasta Kayıtları}

Hastaların demografik özellikleri, evde uzun süreli oksijen tedavisi (USOT) ve NIMV kullanım durumları, SY'nin altta yatan nedenleri, kronik obstrüktif akciğer hastalığ1 (KOAH), obezite hipoventilasyon sendromu (OHS), kas ve toraks deformite hastalıkları, hastane kökenli enfeksiyon, YBÜ öncesi lokasyonları (acil, servis, dış YBÜ), YBÜ’ye girişte ciddiyet skorları (APACHE II, SOFA skoru), NIMV'ın uygulama süreleri (ilk gün, son gün ve toplam gün) ile YBÜ'de ve hastanede kalış süreleri kaydedildi.

\section{Laboratuvar Kayitları}

Hastaların YBÜ'de ilk gün hemogram, biyokimya değerleri ve C-reaktif protein (CRP) değerleri kayıt edildi. Her gün hemogram ve elektrolit kontrolü, 3 gün ara ile CRP biyokimya değerleri kontrol edildi. Giriş AKG değerleri kayıt edildi.

\section{Hastaların Gruplandırılması}

NIMV'de karbondioksit yanıtına göre nazal oksijene geçildikten sonra $\mathrm{PaCO}_{2}$ 'de $8 \mathrm{mmHg}$ artı̧̧ olanlar grup 1 (değişken $\mathrm{PaCO}_{2}$ ), olmayanlar grup 2 (stabil azalan $\mathrm{PaCO}_{2}$ ) olarak sinıflandırıldı. 


\section{BULGULAR}

Çalışma döneminde NIMV endikasyonu olup ilk AKG kontrolünde entübe edilmeyen 204 hastanın AKG da $\mathrm{pH} \leq 7,34$ ve $\mathrm{PaCO}_{2}>45 \mathrm{mmHg}$ olan 139'u çalıșmaya dahil edildi.

Hastaların demografik özellikleri, YBÜ’ye girişte ciddiyet skorları, NIMV'nin uygulama süreleri (ilk gün, son gün ve toplam gün) ile YBÜ'de ve hastanede kalış süreleri Tablo 1'de özetlendi. Mekanik ventilasyondan ayırma (weaning) denemelerinde spontan solunumda $\mathrm{PaCO}_{2}$ 'de $8 \mathrm{mmHg}$ artış başarısızlık kriteri olarak kabul edilir. Çalışmamızda nazal oksijende $\mathrm{AKG}$ 'de $\mathrm{PaCO}_{2}$ yanitları değerlendirildi. Hastaların 81'inde nazal oksijende karbondioksit değerlerindeki artış $<8 \mathrm{mmHg}$ altında iken (grup 2) 58 hastada (grup 1) $\mathrm{PaCO}_{2}$ değerinde $8 \mathrm{mmHg}$ ve üzeri artış gözlendi. Toraks deformitesi-kas hastalıkları olanların \%83,3'ünde NIMV uygulamasina iyi yanıt alınmasina karşın, nazal oksijen tedavisine geçildikten kısa süre sonra $\mathrm{PaCO}_{2}$ değerlerinde hızla yükselme gösterdikleri saptandı. Bununla birlikte parankimal hastalığı olanların \%78,9'unda nazal oksijen ile karbondioksit değerlerinde yükselme gözlenmedi. Nazal oksijen ile KOAH hastalarının \%40,6'sinda $\mathrm{PaCO}_{2}$ artarken, OHS hastalarının \%55,6'sinda nazal oksijen ile $\mathrm{PaCO}_{2}$ 'de artış oldu $(\mathrm{p}<0,028)$ (Şekil 1). Grup 1 ve 2'nin evde USOT ve NIMV kullanım oranları benzerdi (Şekil 2). Her iki grup, demografik özellikleri ile YBÜ giriş ciddiyet skorları karşılaştırıldığında benzer oldukları görüldü (Tablo 2). İlk alınan AKG değerleri grup 1 ve grup 2'de benzerdi. NIMV başlandıktan sonra alınan kontrol AKG'de ise grup 1'de pH değeri istatistiksel olarak anlamlı derecede yüksek (grup 1'de ortanca pH 7,36 buna karşın grup 2'de $\mathrm{pH} 7,32$, $\mathrm{p}<0,005$ ) ve $\mathrm{PaCO}_{2}$ anlaml derecede düşük olarak bulundu (grup 1'de ortanca $\mathrm{PaCO}_{2}$ $63,3 \mathrm{mmHg}$ iken grup 2 de $\mathrm{PaCO}_{2} 71,8 \mathrm{mmHg}, \mathrm{p}<0,039$ ). NIMV uygulanmasını takiben hızlı düzelen olguların $\% 41,7$ 'sinin nazal oksijene geçildikten kısa süre sonra tekrar solunumsal asidoza girdikleri gözlendi. NIMV sonrası nazal oksijende takip edilen hastaların AKG'de $\mathrm{pH}$ grup 1'de ortanca değeri 7,30'a gerilerken grup 2'de $\mathrm{pH}$ 7,35’e yükseldi ( $\mathrm{p}<0,000), \mathrm{PaCO}_{2}$ grup 1'de 77,6 mmHg'ya

Tablo 1. Hastaların demografik özellikleri, YBÜ’ye girişte ciddiyet skorları, NIMV'nin uygulama süreleri ile YBÜ'de ve hastanede kalıs süreleri

\begin{tabular}{|lc|}
\hline Değerler & Ortanca \\
\hline Yaş & $(60 \pm 74)$ \\
Cinsiyet, Kadın/Erkek & $43 / 96$ \\
Beden kitle indeksi & $25(21-30)$ \\
YBÜ’ye giriş APACHE II skoru & $18(15-22)$ \\
YBÜ’ye giriş SOFA skoru & $3(3-4)$ \\
YBÜ’ye giriş serum kreatinin (mg/dl) & $1,06(0,88-1,34)$ \\
YBÜ’ye giriş CRP mg/dl & $25(9-61)$ \\
NİMV süre ilk gün (saat) & $12(9-15)$ \\
NİMV süre son gün (saat) & $8(5-12)$ \\
NİMV süre toplam (gün) & $6(4-11)$ \\
YBÜ'de kalış süre (gün) & $6(4-11)$ \\
Hastanede kalış süre (gün) & $12(8-17)$ \\
\hline YBÜ: Yoğun bakım ünitesi; NIMV: Noninvaziv mekanik ventilasyon; CRP: C-reaktif \\
protein
\end{tabular}

yükselirken grup 2'de $\mathrm{PaCO}_{2}$ 66,7 mmHg'ya geriledi $(p<0,000)$. Her iki grubun YBÜ’den çıkış AKG değerleri benzerdi. Grupların nazal oksijen ve NIMV'deki $\mathrm{PaCO}_{2}$ değerlerinde değişkenlik görülmesine rağmen, çıkış AKG değerleri farklılık göstermiyordu (Tablo 2).

\begin{tabular}{|c|c|c|c|}
\hline & Grup 1 & Grup 2 & $\mathbf{p}$ \\
\hline Yaş (yıl) & $59 \pm 71$ & $60 \pm 76$ & 0,09 \\
\hline VKI & $26(23-30)$ & $25(21-30)$ & 0,48 \\
\hline $\begin{array}{l}\text { YBÜ’ye giriş } \\
\text { APACHE II skoru }\end{array}$ & $\begin{array}{c}18 \\
(14-21)\end{array}$ & $\begin{array}{c}19 \\
(17-22)\end{array}$ & 0,11 \\
\hline $\begin{array}{l}\text { YBÜ'ye giriş SOFA } \\
\text { skoru }\end{array}$ & $\begin{array}{c}3 \\
(2-4)\end{array}$ & $\begin{array}{c}3 \\
(3-4)\end{array}$ & 0,94 \\
\hline $\begin{array}{l}\text { YBÜ’ye giriş } \\
\text { kreatinin (mg/dl) }\end{array}$ & $\begin{array}{c}1,07 \\
(0,79-1,39)\end{array}$ & $\begin{array}{c}1,05 \\
(0,88-1,34)\end{array}$ & 0,81 \\
\hline $\begin{array}{l}\text { YBÜ'ye giriş CRP } \\
(\mathrm{mg} / \mathrm{dl})\end{array}$ & $\begin{array}{c}20 \\
(10-50)\end{array}$ & $\begin{array}{c}27 \\
(9-71)\end{array}$ & 0,41 \\
\hline YBÜ’ye giriş pH & $\begin{array}{c}7,27 \\
(7,24-7,30)\end{array}$ & $\begin{array}{c}7,28 \\
(7,22-7,31)\end{array}$ & 0,78 \\
\hline $\begin{array}{l}\text { YBÜ'ye giriş } \mathrm{PaCO}_{2} \\
\mathrm{mmHg}\end{array}$ & $\begin{array}{c}80,0 \\
(73,0-94,0)\end{array}$ & $\begin{array}{c}80,0 \\
(70,5-90,0)\end{array}$ & 0,34 \\
\hline $\begin{array}{l}\text { YBÜ’ye giriş } \mathrm{HCO}_{3} \\
\text { mmol }\end{array}$ & $\begin{array}{c}34,4 \\
(30,7-39,0)\end{array}$ & $\begin{array}{c}33,0 \\
(28,0-39,9)\end{array}$ & 0,35 \\
\hline $\begin{array}{l}\text { YBÜ’ye giriş } \\
\mathrm{PaO}_{2} / \mathrm{FiO}_{2}\end{array}$ & $\begin{array}{c}186 \\
(128-236)\end{array}$ & $\begin{array}{c}188 \\
(121-252)\end{array}$ & 0,91 \\
\hline Kontrol pH & $\begin{array}{c}7,36 \\
(7,30-7,40)\end{array}$ & $\begin{array}{c}7,32 \\
(7,27-7,36)\end{array}$ & 0,005 \\
\hline $\begin{array}{l}\text { Kontrol } \mathrm{PaCO}_{2} \\
\mathrm{mmHg}\end{array}$ & $\begin{array}{c}63,3 \\
(56,3-73,0)\end{array}$ & $\begin{array}{c}71,8 \\
(61,0-82,0)\end{array}$ & 0,039 \\
\hline Kontrol $\mathrm{HCO}_{3}$ & $\begin{array}{c}34,7 \\
(31,0-39,8)\end{array}$ & $\begin{array}{c}35,9 \\
(30,0-39,2)\end{array}$ & 0,90 \\
\hline $\begin{array}{l}\text { Kontrol } \\
\mathrm{PaO}_{2} / \mathrm{FiO}_{2}\end{array}$ & $\begin{array}{c}223 \\
(160-265)\end{array}$ & $\begin{array}{c}200 \\
(142-250)\end{array}$ & 0,12 \\
\hline $\mathrm{Nazal} \mathrm{O}_{2}$ ile $\mathrm{pH}$ & $\begin{array}{c}7,30 \\
(7,27-7,34)\end{array}$ & $\begin{array}{c}7,35 \\
(7,31-7,41)\end{array}$ & 0,000 \\
\hline $\begin{array}{l}\mathrm{Nazal} \mathrm{O}_{2} \text { ile } \mathrm{PaCO}_{2} \\
\mathrm{mmHg}\end{array}$ & $\begin{array}{c}77,6 \\
(66,8-90,0)\end{array}$ & $\begin{array}{c}66,7 \\
(53,5-74,3)\end{array}$ & 0,000 \\
\hline $\mathrm{Nazal} \mathrm{O}_{2}$ ile $\mathrm{HCO}_{3}$ & $\begin{array}{c}35,7 \\
(33,6-39,6)\end{array}$ & $\begin{array}{c}34,5 \\
(29,7-39,3)\end{array}$ & 0,09 \\
\hline $\begin{array}{l}\mathrm{Nazal} \mathrm{O}_{2} \text { ile } \\
\mathrm{PaO}_{2} / \mathrm{FiO}_{2}\end{array}$ & $\begin{array}{c}204 \\
(143-311)\end{array}$ & $\begin{array}{c}195 \\
(138-268)\end{array}$ & 0,39 \\
\hline YBÜ'den çıkış pH & $\begin{array}{c}7,41 \\
(7,38-7,45)\end{array}$ & $\begin{array}{c}7,41 \\
(7,37-7,46)\end{array}$ & 0,96 \\
\hline $\begin{array}{l}\text { YBÜ'den çıkış } \\
\mathrm{PaCO}_{2} \mathrm{mmHg}\end{array}$ & $\begin{array}{c}56,1 \\
(48,0-61,0)\end{array}$ & $\begin{array}{c}55,0 \\
(48,0-60,8)\end{array}$ & 0,82 \\
\hline $\begin{array}{l}\text { YBÜ'den çıkış } \\
\mathrm{HCO}_{3}\end{array}$ & $\begin{array}{c}34,1 \\
(32,0-37,7)\end{array}$ & $\begin{array}{c}34,8 \\
(30,3-37,5)\end{array}$ & 0,70 \\
\hline $\begin{array}{l}\text { YBÜ'den çıkış } \\
\mathrm{PaO}_{2} / \mathrm{FiO}_{2}\end{array}$ & $\begin{array}{c}204 \\
(167-266)\end{array}$ & $\begin{array}{c}228 \\
(180-303)\end{array}$ & 0,13 \\
\hline
\end{tabular}

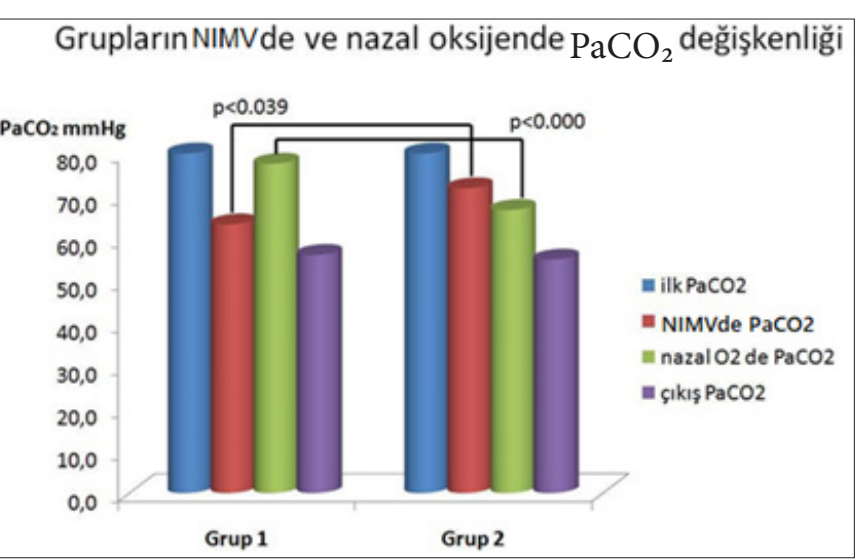

Şekil 1. Grup 1 ve 2'nin nazal oksijen ve NIMV'de $\mathrm{PaCO}_{2}$ değiş̧kenliği NIMV: Noninvaziv mekanik ventilasyon 
Gruplarm USOT ve evde NIMV kullanm oranları

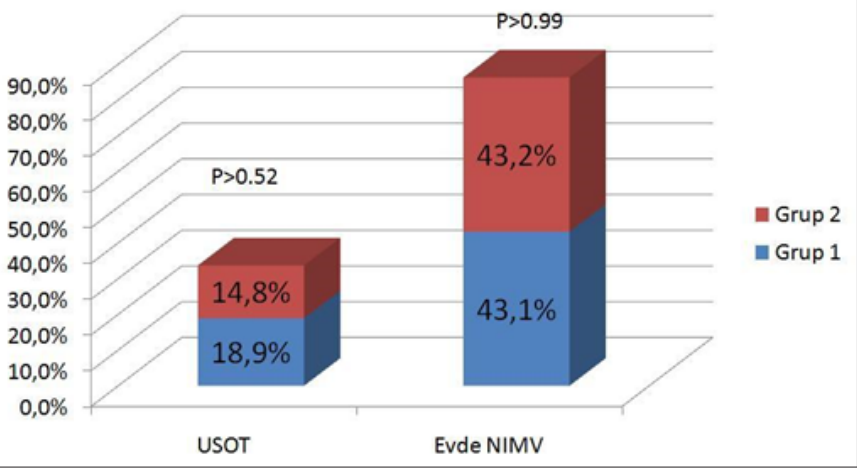

Sekil 2. Grupların YBÜ’ye kabulünde USOT ve evde NIMV kullanma oranları

USOT: Uzun süreli oksijen tedavisi; NIMV: Noninvaziv mekanik ventilasyon

Grupların NIMV uygulama basınçları ve süreleri ile YBÜ ve hastane kalış günleri karşılaştırıldığında benzer bulundu (Tablo 3). Grup 1 hastalarında YBÜ'de ortanca kalma süresi 8 gün olmasına karşın grup 2'de 6 gündü, ancak aralarında istatistiksel olarak anlamlı farklılık bulunmadı (Tablo 3). NIMV başarısızlığı nedeni ile IMV uygulanması ve mortalite açısından gruplar arası istatistiksel açıdan anlamlı fark saptanmadı (Şekil 3).

Tablo 3. NIMV uygulama basınçları, süreleri, YBÜ ve hastanede kalış günleri

\begin{tabular}{|lccc|}
\hline & Grup 1 & Grup 2 & p \\
\hline IPAP & $24(20-26)$ & $23(20-25)$ & 0,57 \\
EPAP & $5(5-6)$ & $5(5-6)$ & 0,16 \\
NIMV ilk gün saat & $12(9-15)$ & $12(9-16)$ & 0,82 \\
NIMV toplam gün & $8(4-11)$ & $6(3-10)$ & 0,27 \\
YBÜ kalış gün & $8(5-12)$ & $6(4-10)$ & 0,12 \\
Hastane kalış gün & $12(8-18)$ & $12(7-17)$ & 0,34 \\
\hline $\begin{array}{l}\text { IPAP: İnspiratuvar pozitif hava yolu basinc; EPAP: Ekspiratuvar pozitif hava yolu } \\
\text { basinci; YBÜ: Yoğun bakım ünitesi; NIMV: Noninvaziv mekanik ventilasyon }\end{array}$ \\
\hline \multicolumn{4}{l}{} \\
\hline
\end{tabular}

Grupların İnvaziv mekanik ventilasyon ve mortalite oranları.

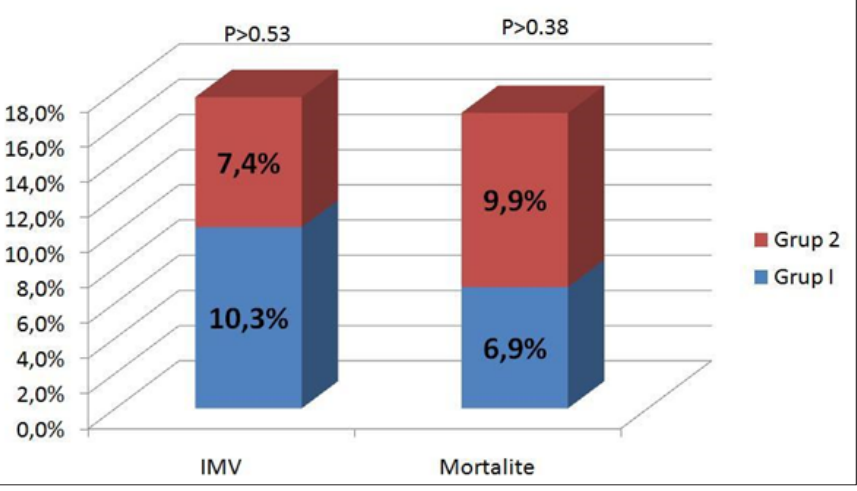

Şekil 3. Grup 1 ve 2'nin IMV ve mortalite oranları IMV: İnvaziv mekanik ventilasyon

\section{TARTIŞMA}

$\mathrm{Bu}$ çalışmada, kas hastalığı ve toraks deformitesi olan hastaların \%83,3'ünde NIMV uygulamasına iyi yanıt alınmasını takiben nazal oksijen tedavisine geçildikten sonra erken dönemde $\mathrm{PaCO}_{2}$ değerlerinde hizlı gelișen yükselme saptandı. Bu oran OHS hastalarında \%55,6 iken; parankimal hastalığı olanlarda \%21,1'idi.

Akut solunum yetmezliğinde NIMV kullanımı uygulama yeri önceleri ileri monitörizasyon yöntemleri gerektirdiğinden önceleri yoğun bakım ünitelerinde uygulanması önerilmekteyken, dünyada ve ülkemizde yapılan çalışmalarda NIMV konusunda deneyimli ekip varlı̆̆ında yoğun bakım ünitesi dışında da uygulanabileceği gösterilmiştir $(6,16)$. NIMV uygulaması, deneyimli bir ekip ile her mekânda yapılabileceği gibi kısa ve uzun dönem NIMV başarısını öngörmek acil servisteki hastanın sonraki aşamada nerede takip edileceğine karar verme açısından önemlidir $(17,18)$. Plant $\mathrm{K}$ ve arkadaşları 13 merkezli yaptıkları çalışmada; göğüs hastalıkları servislerinde NIMV uyguladıkları KOAH hastalarında, geçmişteki KOAH hastalarına göre, mortalitenin \%20 'den \%10'a ve tedavi başarısızlığının (entübasyon ihtiyacı) $\% 27$ 'den \%15'e gerilediğini bildirmiştir (19). Aynı çalışmanın alt grup analizinde $\mathrm{pH}<7,30$ olan hastalarda serviste NIMV başarısızlığının daha yüksek olduğu gösterilmiştir (20). Respiratuvar asidozu olan hastalara acil serviste medikal bronkodilatör tedavi ile birlikte NIMV uygulanarak kısa sürede AKG'de düzelme $\left(\mathrm{PaCO}_{2}\right.$ de düşme ve $\mathrm{pH}$ değerinde yükselme) sağlanmaktadır. Acil servise başvuran hiperkapnik solunum yetmezliğine bağlı respiratuvar asidozu olan hastalarda endikasyon dahilinde NIMV'nin erken kullanımının hastanede kalış süresini kısaltıp komplikasyonları azalttığı, $\mathrm{pH}$ ve $\mathrm{PaCO}_{2}$ 'yi düzelttiği çalışmalarda gösterilmiştir (21-23). Yapılan çalışmalarda AHSY'de $\mathrm{pH}<7,30$ ise, servis yerine YBÜ takibi önerilmekle birlikte deneyimli ekibi olan merkezlerin servislerinde de NIMV uygulayabilecekleri uzman görüşü olarak bildirilmektedir (24). Ancak hızlı değişen $\mathrm{PaCO}_{2}$ değeri nedeni ile NIMV ile elde edilen iyi bir $\mathrm{pH}$ değeri hasta takip yerinin seçiminde çalışma sonuçlarımıza göre yeterli değildir. Çalışmamızda hızla düzelen olguların \%41,7'sinin nazal oksijene geçildikten kısa süre sonra tekrar solunumsal asidoza girdikleri gözlendi. $\mathrm{Bu}$ hastaların yakından izlenmesi gerekliliği nedeni ile YBÜ'de takip edilmeleri gerektiği kanaatindeyiz. Asidoz durumu, hiperkapninin akut veya kronik olmasina göre değişkenlik gösterebilmektedir. Hiperkapnik solunum yetmezliği olan $\mathrm{KOAH}$ hastalarında yapılan bir çalışmada ortalama pH 7,18 olan $64 \mathrm{KOAH}$ hastasının 24'ü başarısız olup entübe edilmiş ancak geciktirilmiş entübasyon ve uzun asidoz maruzuyeti nedeniyle hastalarda olumsuz bir durum bildirilmemiştir (24). Hiperkapnik solunum yetmezliği olan $\mathrm{KOAH}$ hastalarını kapsayan başka bir 
çalışmada; pH 7,25 altındakilerle pH 7,25 üzerindeki hastalar karşılaştırıldığında, NIMV uygulamasındaki başarı oranının benzer olduğu gösterilmiştir (25). Hiperkapnik solunum yetmezliğinde hiperkapniye bağlı gelişen şuur bulanıklığının NIMV uygulanması için bir kontrendikasyon olmadığı bilinmektedir $(1,26)$. Çalışmamızda hastalarda görülen şuur bulanıklığı hızlı değissen AKG değerleri ile paralel olup, hiperkapnide derinleşme olduğunda ciddi uykuya meyil hali gözlendi.

APACHE II, hastalık şiddeti göstergesi olarak kullanılan skorlama yöntemlerinden biri olup, yapılan çalışmalarda APACHE II değerinin yüksek olması NIMV başarısızlığ ile ilişkili bulunmuştur $(12,15,27,28)$. Confalonieri ve ark. (28) çok merkezli, $1033 \mathrm{KOAH}$ atağı olgusunu içeren çalışmalarında APACHE II skorunun 29'dan fazla olmasının NIMV başarısızlığını ön görmede önemli bir belirteç olduğu tespit etmişlerdir. Merkezimizde hastalık ağırlık göstergesi olarak APACHE II skoru kullanılmakta olup, gruplar arasinda APACHE II skorları arasında anlamlı fark bulunmadı. Çalışmamızda NIMV uygulanması sonrası $\mathrm{PaCO}_{2}$ yanıtlarındaki değişkenliklerinin nedenleri araştırıldığında, YBÜ’ye girişteki demografik özellikleri ve AKG değerleri arasında bir fark bulunmadı. Ancak $\mathrm{PaCO}_{2}$ değişkenliği gösteren grupta, kronik hipoventilasyona neden olan (gögüs duvarı deformitesi ile OHS) hastalıklar fazlaydı. Kronik fiziksel patolojilerde (göğüs duvarı hastalıkları ve obezite) AKG değisşkenliğinin tahmin edilebilir bir bulgu olduğunu bu çalışmadaki verilere dayanarak düşünmekteyiz. Bu grup hastalarda $\mathrm{AKG}$ değerlerinde düzelmenin geri dönüşümlü olduğu dikkate alınarak hastaneye yatmasını gerektirecek solunum yetmezliği tedavisinin YBÜ'de yapılmasının daha uygun olacağını düşünmekteyiz.

Noninvaziv mekanik ventilasyon uygulanmasının başarı değerlendirmesinde ilk 1-2 saat önemli olup AKG değerleri bakılmasına yönelik bir grup çalışma bildirilmiş, rehberlere de dayanak olmuştur $(9,27,29)$. Ancak çalışmamızda, NIMV uygulanması yanıtı sonrasında nazal oksijen ile takiplerinde bir grup hastanın başa dönüp tekrar ciddi hiperkapniye ve asidoza girdiğini saptadık.

Noninvaziv mekanik ventilasyon uygulanmasının hastane kalış süresini kısalttığı, İMV ihtiyacını azalttığı, solunum işini azalttığı KOAH ve hiperkapninin eşlik ettiği kardiyojenik ödemli hastalarda bildirilmiştir (30-33). Çalışmada $\mathrm{PaCO}_{2}$ değeri yavaş ve emin adımlarla azalan grubun YBÜ ve hastane kalıs günü yaklaşık diğer gruptan 2 gün kısa olup her ne kadar istatistiksel anlamlı olmasa da maliyeti düşürmektedir. YBÜ kalış günü uzun olduğundan mortalite riski de artmaktadır. Akut solunum yetmezliği nedeniyle NIMV uygulanan obez hastaların AKG değerlerinin normal aralığa dönmesi obez olmayanlara göre daha uzun sürmektedir (34).
Çalışmadaki sınırlayıcı durumlar; geriye dönük gözlemsel araştırma olup veriler dosyalardan kayıt edilmiştir. Gruplarımızın solunum ve sistemik kas fonksiyonlarını değerlendiren ölçüm ve araştırma yapılmamıştır. Hastalarımızın solunum fonksiyon testleri, bronkodilatör yanıtları hakkında veri bulunmadığından değerlendirmeye alınmamıştır.

\section{SONUÇ}

$\mathrm{Bu}$ çalışmada AHSY gelişmiş toraks deformitesi-kas hastalığı ve OHS hastalarında NIMV'ye iyi yanıt alınmış olmasına rağmen nazal oksijenle takip sırasında erken dönemde yeniden respiratuvar asidoz gelişme sıklığının oldukça yüksek olduğunu gördük. Acil serviste AHSY nedeniyle NIMV uygulanan hastalarda tedaviye erken dönemde iyi cevap alınması bu hastaların YBÜ yerine servise yatı̧ kararının verilmesinde yanıltıcı olabilir. $\mathrm{Bu}$ hastaların takip ve tedavisinin nerede yapılacağına nazal oksijen tedavisi sonrası karar verilmesinin uygun olacağını düşünmekteyiz.

\section{ETIKK BEYANLAR}

Etik Kurul Onayı: Çalışmamız Süreyyapaşa Göğüs Hastalıkları ve Göğüs Cerrahisi Eğitim ve Araştırma Hastanesi Etik Kurulu tarafından onaylanmıştır (2011/2).

Aydınlatılmış Onam: Çalışma retrospektif olarak dizayn edildiği için hastalardan aydınlatılmış onam alınmamıştır.

Hakem Değerlendirme Süreci: Harici çift kör hakem değerlendirmesi.

Çıkar Çatışması Durumu: Yazarlar bu çalışmada herhangi bir çıkara dayalı ilişki olmadığını beyan etmişlerdir.

Finansal Destek: Yazarlar bu çalışmada finansal destek almadıklarını beyan etmişlerdir.

Yazar Katkıları: Yazarların tümü; makalenin tasarımına, yürütülmesine, analizine katıldığını ve son sürümünü onayladıklarını beyan etmişlerdir.

\section{KAYNAKLAR}

1. Bello G, De Pascale G, Antonelli M. Noninvasive ventilation. Clin Chest Med 2016; 37: 711-21.

2. Schnell D, Timsit JF, Darmon M, et al. Noninvasive mechanical ventilation in acute respiratory failure: trends in use and outcomes. Intensive Care Med 2014; 40: 582-91.

3. Demoule A, Chevret S, Carlucci A, et al. Changing use of noninvasive ventilation in critically ill patients: trends over 15 years in francophone countries. Intensive Care Med 2016; 42: 82-92.

4. Demoule, A, Girou, E, Richard, JC, et al. Increased use of noninvasive ventilation in French intensive care units. Intensive Care Med 2006; 32: 1747.

5. Maheshwari V, Paioli D, Rothaar R, et al. Utilization of noninvasive ventilation in acute care hospitals: a regional survey. Chest 2006; 129: 1226-33. 
6. Dikensoy O, İkidağ B, Filiz A, Bayram N. Comparison of noninvasive ventilation and standard medical therapy in acute hypercapnic respiratory failure: A randomised controlled study at a tertiary health centre in SE Turkey. Int J Clin Pract 2002; 56: 85-8.

7. International Consensus Conferences in Intensive Care Medicine: noninvasive positive pressure ventilation in Acute Respiratory Failure. Am J Respir Crit Care Med 2001; 163: 283-91.

8. Diaz GG, Alcaraz AC, Talavera JC, et al. Noninvasive positivepressure ventilation to treat hypercapnic coma secondary to respiratory failure. Chest 2005; 127: 952-60.

9. Evans TW. International Consensus Conferences in Intensive Care Medicine: Noninvasive positive pressure ventilation in acute respiratory failure. organised jointly by the American Thoracic Society, the European Respiratory Society, the European Society of Intensive Care Medicine, and the societe de Reanimation de Langue Francise, and approved by the ATS Boart of Direction. Intensive Care Med 2001; 27: 166-78.

10. Schönhofer B, Kuhlen R, Neumann P, Westhoff M, Berndt C, Sitter $\mathrm{H}$. Clinical practice guideline: non-invasive mechanical ventilation as treatment of acute respiratory failure. Deutch Arztebl Int 2008; 105: 424-33.

11. Celikel T, Sungur M, Ceyhan B, Karakurt S. Comparison of noninvasive positive pressure ventilation with standard medical therapy in hypercapnic acute respiratory failure. Chest 1998; 114: 1636-42.

12. Ozyilmaz E, Ozsancak Ugurlu A, Nava S. Timing of noninvasive ventilation failure: causes, risk factors, and potential remedies. BMC Pulm Med. 2014; 14: 19.

13. Garpestad E, Brennan J, Hill NS. Noninvasive ventilation for critical care. Chest 2007; 132: 711-20.

14. Nicolini A, Ferrera L, Santo M, Ferrari-Bravo M, Del Forno M, Sclifò F. Noninvasive ventilation for hypercapnic exacerbation of chronic obstructive pulmonary disease: factors related to noninvasive ventilation failure. Pol Arch Med Wewn 2014; 124: 525-31.

15. Kaya A, Çiledağ A, Çaylı İ, Önen ZP, Şen E, Gülbay B. Associated factors with non-invasive mechanical ventilation failure in acute hypercapnic respiratory failure. Tuberk Toraks. 2010; 58: 128-34.

16. Ciledag A, Kaya A, Akdogan BB, et al. Early use of noninvasive mechanical ventilation in patients with acute hypercapnic respiratory failure in a respiratory ward: a prospective study. Arch Bronconeumol 2010; 46: 538-42.

17. Vitacca $M$. Where and how must we perform noninvasive mechanical ventilation? Monaldi Arch Chest Dis 1997; 52: 80-2.

18. Elliott MW, Confalonieri M, Nava S. Where to perform noninvasive ventilation? Eur Respir J 2002; 19: 1159-66.

19. Plant PK, Owen JL, Elliot MW, et al. Early use of non-invasive ventilation for acute exacerbations of chronic obstructive pulmonary disease on general respiratory wards: A multicentre randomized controlled trial. Lancet 2000; 355: 1931-5.

20. Allison MG, Winters ME. Noninvasive ventilation for the emergency physician. Emerg Med Clin North Am. 2016; 34: 51-62.

21. Ram FS, Picot J, Lightowler J, Wedzicha JA. Non-invasive positive pressure ventilation for treatment of respiratory failure due to exacerbations of chronic obstructive pulmonary disease. Cochrane Database Syst Rev. 2004; 3: CD004104.

22. Berbenetz N, Wang Y, Brown J, et al. Non-invasive positive pressure ventilation (CPAP or bilevel NPPV) for cardiogenic pulmonary oedema. Cochrane Database Syst Rev. 2019; 4: CD005351.

23. Acartürk Tunçay E, Güngör S, Ocaklı B. Noninvasive mechanical ventilation failure and long-term follow-up results of failure in hypercarbic respiratory failure. Duzce Medical Journal 2019; 21: 54-60.

24. Crummy F, Buchan C, Miller B, et al. The use of noninvasive mechanical ventilation in COPD with severe hypercapnic acidosis. Respiratory Medicine 2007; 101: 53-61.
25. Bacakoğlu F, Taşbakan MS, Kaçmaz Başoğlu O, et al. The factors affecting noninvasive mechanical ventilation failure in COPD exacerbations. Turk J Med Sci. 2012; 42: 103-12.

26. Honrubia T, Garcia Lopez FJ, Franco N, et al. Noninvasive vs conventional mechanical ventilation in acute respiratory failure: $\mathrm{A}$ multicenter, randomized controlled trial. Chest 2005; 128: 391624.

27. Confalonieri M, Garuti G, Cattaruzza MS, et al. A chart of failure risk for noninvasive ventilation in patients with COPD exacerbation. Eur Respir J. 2005; 25: 348-55.

28. Çiledağ A, Kaya A, Erçen Diken Ö, Önen ZP, Şen E, Demir N. The risk factors for late failure of noninvasive mechanical ventilation in acute hypercapnic respiratory failure. Tuberk Toraks 2014; 62: 177-82.

29. Antonelli M, Conti G, Moro ML, et al. Predictors of failure of noninvasive positive pressure ventilation in patients with acute hypoxemic respiratory failure: a multicenter study. Intensive Care Med 2001; 27: 1718-28.

30. Liesching T, Kwok H, Hill NS. Acute applications of noninvasive positive pressure ventilation. Chest 2003; 124: 699-713.

31. Nava S, Carbone G, DiBattista N, et al. Noninvasive ventilation in cardiogenic pulmonary edema: a multicenter randomized trial. Am J Respir Crit Care Med 2003; 168: 1432-7.

32. Crane SD, Elliott MW, Gilligan P, et al. Randomised controlled comparison of continuous positive airways pressure, bilevel non-invasive ventilation, and standard treatment in emergency department in patients with acute cardiogenic pulmonary oedema. Emerg Med J 2004; 21: 155-61.

33. Gray A, Goodacre S, Newby DE, et al. Noninvasive ventilation in acute cardiogenic pulmonary edema. N Engl J Med 2008; 359: 142-51.

34. Güsel G, Aydoğdu M, Gülbaş G, Özkaya S, Taşyürek S, Yıldırım F. The influence of severe obesity on non-invasive ventilation (NIMV) strategies and responses in patients with acute hypercapnic respiratory failure attacks in the ICU. Minerva Anestesiol 2011; 77: $17-25$. 